\title{
Evidence of a Possible Decline since 1989 in False Killer Whales (Pseudorca crassidens) around the Main Hawaiian Islands ${ }^{1}$
}

\author{
Randall R. Reeves, ${ }^{2}$ Stephen Leatherwood, ${ }^{3}$ and Robin W. Baird ${ }^{4,5}$
}

\begin{abstract}
Recent evidence indicates that there is a small, demographically isolated, island-associated population of false killer whales (Pseudorca crassidens) around the main Hawaiian Islands. Although it is known that false killer whales in Hawai' $i$ are sometimes killed or seriously injured in the Hawai'i-based longline fishery, it is not known whether such interactions have resulted in a reduction in population size or whether other factors have been negatively influencing population size. We report the results of an aerial survey in June and July 1989, the purpose of which was to obtain a minimum count of the number of false killer whales around the main Hawaiian Islands. The false killer whale was the third most commonly seen species of odontocete off the island of Hawai'i during the survey, representing $17 \%$ of sightings. Groups of more than 300 individuals were seen on three different days, with minimum counts of 380,460 , and 470 individuals in these groups. The encounter rate, relative species ranking, and average group size from the 1989 survey were all substantially greater than those from more recent aerial and ship-based surveys. The largest group observed in 1989 (470) contained almost four times as many whales as estimated for the entire main Hawaiian Islands from recent aerial surveys (121 individuals, $\mathrm{CV}=0.47)$ or mark-recapture analyses $(123$ individuals, $\mathrm{CV}=0.72)$. Therefore, the population of false killer whales around the main Hawaiian Islands may have declined substantially since 1989 . The cause or causes of such a decline are uncertain.
\end{abstract}

RECENT GENETIC AND photo-identification evidence indicates the existence of a demographically isolated, island-associated population of false killer whales, Pseudorca crassidens (Owen), around the main Hawaiian Islands (Chivers et al. 2007, Baird et al. 2008). False killer whales around the main Hawaiian Islands are genetically differentiated from those in the outer part of the Hawaiian Exclusive Economic Zone and the surrounding waters

\footnotetext{
${ }^{1}$ Manuscript accepted 5 June 2008.

${ }^{2}$ Okapi Wildlife Associates, 27 Chandler Lane, Hudson, Quebec J0P 1H0, Canada.

${ }^{3}$ Deceased.

${ }^{4}$ Author for correspondence.

${ }^{5}$ Cascadia Research Collective, $218 \frac{1}{2}$ West 4th Avenue, Olympia, Washington 98501 (e-mail: rwbaird@ cascadiaresearch.org).
}

Pacific Science (2009), vol. 63, no. 2:253-261

(C) 2009 by University of Hawai'i Press

All rights reserved of the central tropical Pacific (Chivers et al. 2007), although it is unknown how much the ranges of the two groups overlap. Estimates of the island-associated population are available from two sources: aerial surveys in 1993, 1995, and 1998 (Mobley et al. 2000) and mark-recapture analysis of photo-identification data collected from 2000 through 2004 (Baird et al. 2005). The estimate from aerial surveys was $121(\mathrm{CV}=0.47)$, and the estimate from mark-recapture was $123(\mathrm{CV}=$ 0.72 ). Evidence from dorsal fin disfigurements suggests that the island-associated population is involved in fishery interactions of some kind (Baird and Gorgone 2005). False killer whales are killed and seriously injured in the Hawai'i-based long-line fishery (Forney and Kobayashi 2007). The rate of mortality and serious injury in this fishery is greater than the total population within the Hawaiian Exclusive Economic Zone, both the island-associated whales and those in the outer Exclusive Economic Zone, is thought 
to be able to sustain (Carretta et al. 2007). Whether the bycatch in the long-line fishery has resulted in a population decline is unknown. The two available population estimates, one from the mid- to late 1990s and one from the early to mid-2000s, are too imprecise for a meaningful trend analysis, and there is no information on how the bycatch should be apportioned between the islandassociated and the outer Exclusive Economic Zone populations. Here we report on an aerial survey in 1989 that provided a minimum count of false killer whales around the main Hawaiian Islands. We also consider the implications of this minimum count in relation to the question of the island-associated population's current status.

\section{MATERIALS AND METHODS}

In June and July 1989 an aerial survey was flown along various portions of the lee (western and southwestern) shores of the islands of Hawai'i, Lāna'i, and O'ahu. The purpose of the survey was to obtain a minimum count of false killer whales around the main Hawaiian Islands that could be used in an application for a live-capture permit. The survey was made from a fixed-wing, twoengine aircraft (Partenavia P68C) flying at approximately $229 \mathrm{~m}$ (750 ft) above sea level and a speed of approximately $167 \mathrm{~km} / \mathrm{hr}(90$ knots), although the speed and altitude were varied when necessary to improve navigational fixes and confirm species identifications. The two principal observers (R.R.R., S.L.) were both experienced in identifying a diversity of cetaceans from aerial platforms. On the first day of surveys the plane followed a zigzag pattern from the coast of the island of Hawai'i out to about $55 \mathrm{~km}$ from shore (Figure 1). Two types of surveys were undertaken: general surveys, with broad geographic coverage and where all species observed were recorded, and directed surveys targeting areas where false killer whales had been sighted on previous days. Once located, a group of cetaceans was orbited until the species was identified and the two principal observers were satisfied that they had a minimum count (false killer whales) and/or an acceptable estimate (other species). To obtain minimum counts, each observer logged his counts independently on each orbit until he considered that the number detected had peaked and stabilized. The observers then discussed the figures and agreed on a minimum count to be logged for that sighting. Locations of sightings were determined using loran and noted on a nautical chart. Distances of sightings from shore were determined by reference to plotted chart locations and are thus likely only accurate to $\pm 1 \mathrm{~km}$. Photographs were taken to document species and indicate relative sizes of groups encountered. In most sightings of false killer whales, and in all of them involving more than approximately 30 individuals, it was clear that animals at the surface were being replaced frequently by animals coming to the surface from some depth. Therefore, each photograph provided only a static view of the groups at the surface at a given instant, and the counts from photographs alone were considered negatively biased.

\section{RESULTS}

Thirty survey hours were flown on eight days from 23 June 1989 through 2 July 1989, with $20 \mathrm{hr}$ off the island of Hawaici, $5 \mathrm{hr}$ off the island of Lāna'i, and $4.5 \mathrm{hr}$ off the island of O'ahu (Table 1). The flights off Lāna'i and O'ahu were general surveys, as were 2 days of flights (totaling $13.5 \mathrm{hr}$ ) off Hawai'i. During general surveys (total $23 \mathrm{hr}$ ) conditions were considered excellent for all but $2 \mathrm{hr}$ of effort off O'ahu. The general surveys off the island of Hawai'i produced 30 sightings of odontocetes from nine different species, including five sightings of groups of false killer whales (Table 2). Focused surveys off the island of Hawai'i resulted in an additional nine sightings of false killer whales, with at least one sighting during each day with survey coverage. No sightings of false killer whales were made off other islands, although six other species of odontocetes were sighted.

The number of orbits of groups to determine minimum numbers ranged from 1 to 16 $($ median $=3)$. Minimum group sizes of false killer whales ranged from 2 to 470 individuals 


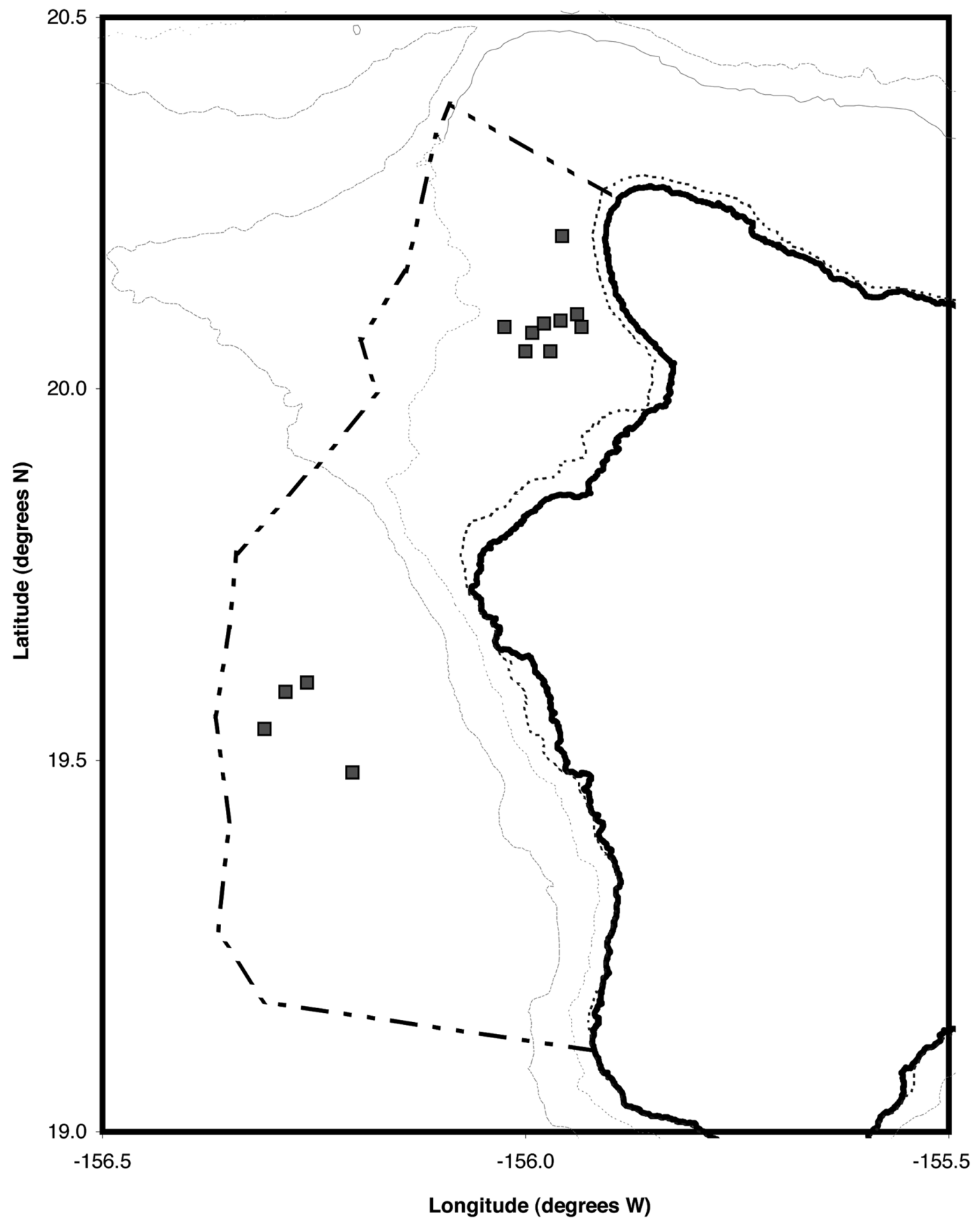

Figure 1. Map showing approximate boundary of general survey area (heavy dashed line) off the island of Hawai' $i$ and locations of false killer whale sightings (squares) in 1989. The $100 \mathrm{~m}$ (dotted line near shore), 1,000 m, and 2,000 m isobaths are shown. The largest groups observed ( $>300$ individuals) were all in the cluster of sightings in the northern part of the survey area. These surveys were undertaken before availability of GPS mapping capability and therefore the exact survey lines flown were not recorded. 
TABLE 1

Summary of Aerial Survey Effort in June-July 1989

\begin{tabular}{lcc}
\hline \hline Island & $\begin{array}{c}\text { No. of Days (hr) } \\
\text { General Surveys }\end{array}$ & $\begin{array}{c}\text { No. of Days (hr) } \\
\text { Directed Surveys }\end{array}$ \\
\hline Hawai'i & $2(13.5)$ & $4(7)$ \\
Lāna'i & $2(5.0)$ & - \\
O'ahu & $2(4.5)$ & - \\
\hline
\end{tabular}

(median $=35.5)$. Sizes of groups orbited three or more times ranged from 11 to 470 (median $=195$ individuals). Groups of more than 300 individuals were seen on three separate occasions: 460 on 23 June (after 11 passes), 470 on 26 June (after 14 passes), and 380 on 28 June (after 7 passes). The group on 23 June consisted of two large subgroups and six to eight small satellite groups, distributed over an area of several square kilometers. From a series of photographs of the two main groups, a minimum of 283 individuals was counted. Although repeated orbits did lead to more accurate assessments of minimum group size in most cases, some of the groups orbited repeatedly were relatively small (79 individuals, 24 June, 16 passes; 27 individuals, 24 June, 4 passes), suggesting that multiple orbits of groups did not result in inflated group size counts. All three of the largest groups of individuals were seen off the western side of the Kohala Peninsula, at distances of approximately 4.5 to $11 \mathrm{~km}$ from shore (Figure 1).

\section{DISCUSSION}

Sighting locations of island-associated false killer whales in directed surveys around the main Hawaiian Islands since 2000 have ranged from 1.6 to $31.9 \mathrm{~km}$ from shore (median $=8 \mathrm{~km}$ [R.W.B., unpubl. data]), whereas the nearest sighting of a group of putatively offshore individuals was some 42 $\mathrm{km}$ from shore (Baird et al. 2008). Given the repeated sightings in 1989 of large groups over a number of days at distances of approximately 4.5 to $11 \mathrm{~km}$ from the island of Hawai' $i$, it is likely that those groups belonged to the island-associated population rather than an offshore population. Further, it seems unlikely that the entire islandassociated population of false killer whales would have been concentrated in a single area at the time of the 1989 survey and therefore it is plausible that the true size of that population in 1989 was at least somewhat greater than 470, the size of the largest group observed. The area where the sightings of large groups were made in 1989 is an area used repeatedly by two satellite-tagged false killer whales, both members of the islandassociated population, over a 4-day period in August 2007 (R.W.B., G. S. Schorr, D. L. Webster, D. J. McSweeney, M. B. Hanson, and R. D. Andrews, unpubl. data).

Comparison of sighting rates and the minimum group sizes of false killer whales obtained in the 1989 aerial survey with the results of recent surveys suggests that the population of false killer whales around

TABLE 2

Odontocete Sightings off the Island of Hawai'i during the 2 Days (13.5 hr) of General Surveys in 1989

\begin{tabular}{lcc}
\hline \hline Species & No. (\%) of Sightings & Group Size Median (range) \\
\hline Pantropical spotted dolphin, Stenella attenuata & $8(26.7)$ & $89(4-500)$ \\
Bottlenose dolphin, Tursiops truncatus & $6(20.0)$ & $3(1-5)$ \\
False killer whale, Pseudorca crassidens & $5(16.7)$ & $27(2-470)$ \\
Spinner dolphin, Stenella longirostris & $3(10.0)$ & $2(1-3)$ \\
Short-finned pilot whale, Globicephala macrorynchus & $2(6.7)$ & $26(20-32)$ \\
Rough-toothed dolphin, Steno bredanensis & $2(6.7)$ & $33(16-50)$ \\
Sperm whale, Physeter macrocephalus & $2(6.7)$ & $2.5(2-3)$ \\
Pygmy killer whale, Feresa attenuata & $1(3.3)$ & 15 \\
Melon-headed whale, Peponocephala electra & $1(3.3)$ & 400 \\
\hline
\end{tabular}


the main Hawaiian Islands has declined over the last $20 \mathrm{yr}$. In the 1989 general surveys off the island of Hawai' $i$, the false killer whale was the third most frequently sighted species of the nine documented, representing 17\% of all sightings. In 369 days of boat-based surveys around all the main Hawaiian Islands from 2000 through 2006, undertaken throughout the year, false killer whales accounted for only $1.5 \%$ of odontocete groups sighted, and the false killer whale was the 11th most frequently encountered species of odontocete (Baird et al. 2008). If the comparison is restricted to boat-based efforts only off the island of Hawai' $i$, the false killer whale remains the 11 th most frequently encountered species of odontocete, representing less than $2 \%$ of 579 odontocete sightings (R.W.B., unpubl. data). Group sizes from the 2000 through 2006 boat-based surveys ranged from 3 to 41 individuals (median $=15$ ), even though encounter durations lasted up to $8 \mathrm{hr}$ (median $=3.0 \mathrm{hr}$ ) and attempts were made to observe and photoidentify all individuals present (Baird et al. 2008). Group size was positively related to encounter duration for these boat-based surveys, with encounters lasting more than $2 \mathrm{hr}$ having a median group size of 25 . By comparison, during the 1989 aerial surveys the median size of groups circled three or more times was 195 individuals. Although not quantified, one researcher working in the area yearly since the mid-1980s has noted that encounter rates with false killer whales off the island have declined since then (D. J. McSweeney, pers. comm.).

Aerial survey data since 1993 from around the entire main Hawaiian Island chain, covering waters out to $46 \mathrm{~km}$ from shore, also indicate a decline. In the 1990s (1993, 1995, 1998) with $239 \mathrm{hr}$ of aerial survey effort, Mobley et al. (2000) made 18 sightings of false killer whales. In an additional $59 \mathrm{hr}$ of aerial surveys in 2000 and $66 \mathrm{hr}$ of aerial surveys in 2003, covering the same area, no false killer whales were observed (J. Mobley, pers. comm.; Mobley 2004). In the 2003 surveys there were 54 sightings of at least 10 other species of odontocetes (Mobley 2004). The sea conditions were less than optimal for these surveys because they covered both the windward and leeward sides of the islands (Mobley et al. 2000, Mobley 2004). Nevertheless, the species sighted included a number of smaller odontocetes that are less likely to be detected from the air than false killer whales. Although the aerial surveys since 1993 were undertaken between January and April of each year (Mobley et al. 2000, Mobley 2004), evidence from boat-based photoidentification studies undertaken year-round suggests that individual false killer whales use the area around the main Hawaiian Islands year-round (Baird et al. 2008). Nineteen of the 21 individual false killer whales that were photo-identified on four or more occasions were seen in either two (nine individuals) or three (10 individuals) of Hawai'i's four oceanographic seasons (Baird et al. 2008).

Because the information on population size takes such different forms (a minimum count in 1989, a line-transect estimate in the mid- to late 1990s, and a mark-recapture estimate in the early to mid-2000s), it is not possible to determine whether there has been a statistically significant decline in the population. Nevertheless, considering that the largest group of false killer whales observed in 1989 (470 individuals) contained almost four times as many individuals as the currently estimated total number of individuals in the island-associated population (Mobley et al. 2000, Baird et al. 2005), a large decline in abundance is a hypothesis that deserves serious consideration.

Possible causes of such a decline include mortality in the Hawai'i-based long-line fishery or in the nearshore troll or other fisheries, health or reproductive effects of high levels of toxins, and/or a reduction in the prey base due to fishing or oceanic factors. No information is available on toxin levels in this population, although false killer whales are known to feed at high trophic levels, targeting large game fish (Shallenberger 1981, Baird et al. 2008), and false killer whales elsewhere have been found to have very high tissue levels of organochlorine pollutants (e.g., Baird et al. 1989). Biomass of some large pelagic fish known to be part of the diet of this population, including yellowfin 
tuna (Tbunnus albacares), has declined in the Pacific (Sibert et al. 2006), and data on catch per unit effort for yellowfin tuna caught in the troll fishery around the main Hawaiian Islands have shown a significant decline over the period from 1987 through 2006 (Anonymous 2006). Average body weight of mahimahi (Coryphaena bippurus) caught in the Hawai'i-based long-line fishery has also declined significantly since 1987 (Anonymous 2006). These data, in combination, provide some support for the hypothesis that reductions in prey biomass have affected the foraging ecology, if not the health and numbers, of false killer whales in Hawaiian waters.

Ross (1984) remarked on the difference between the sizes of groups of false killer whales observed at sea (usually fewer than 50 and often fewer than 20; also see Stacey et al. [1994]) and the sizes of groups involved in mass strandings (50-835 animals, mean $=$ $180, n=14$ [Ross 1984]). Ross speculated that the latter might be "composed of smaller groups that have joined for a purpose, possibly during exploitation of a locally abundant, migrating population of cephalopods." The group sizes observed in 1989 off the island of Hawai'i were exceptionally large and, although unlikely, it is conceivable that a mass stranding occurred some time after July 1989 that would have dramatically reduced numbers locally. However, no mass strandings of false killer whales have been registered in Hawai' $i$, and only one stranding of a single individual has been documented since July 1989 (Maldini et al. 2005). Another possibility is that the very large aggregation in 1989 was a short-term phenomenon resulting from the convergence of offshore and inshore animals, perhaps onto a prime feeding area (possibly contributing to local changes in availability of tuna and mahimahi [see later in this section]) or, alternatively, for social purposes. This possibility is supported by the fact that some false killer whales from the inshore population appear to share haplotypes with animals sampled elsewhere in the Pacific (Chivers et al. 2007).

Another possible cause of a decline is mortality in the Hawai'i-based long-line fishery or in various nearshore fisheries. The long- line fishery expanded rapidly in the late 1980s (Pooley 1993), and this increase was followed in 1992 by restrictions on the fishery from operating around the main Hawaiian Islands. The boundaries of the protected species area vary by time of year, with fishing allowed closest to the islands from the start of October through the end of January each year. During this period fishing operations may occur at a minimum distance of $45 \mathrm{~km}$ from parts of the main Hawaiian Islands, while during other times of the year the closest the fishery may occur from the islands is approximately $79 \mathrm{~km}$. A satellite-tagged false killer whale from the island-associated population moved as far as $96 \mathrm{~km}$ from shore during a 32-day period in August/September 2007 (R.W.B. et al. unpubl. data), so it is possible that the island-associated population interacts with the long-line fleet year-round. The fishery targets either tuna or swordfish, and false killer whales are killed or seriously injured primarily in sets targeting tuna (Forney and Kobayashi 2007). The number of trips targeting tuna more than doubled in the period 2002-2006 versus the period from the early through the mid-1990s (Anonymous 2006), although it must be noted that these trips can include fishing both within and far outside the Hawaiian Exclusive Economic Zone. Interactions do occur with several nearshore commercial and recreational fisheries (Nitta and Henderson 1993, Rhodes et al. 2007), although there are no observer programs for these fisheries, and thus whether such interactions result in serious injury or mortality is not known.

There are, of course, alternative hypotheses other than population decline that could explain the large differences in sighting rates, group sizes, and total numbers between 1989 and more recent years. Among these are that: (1) differences in sighting platforms, survey methods, and/or observer ability and experience led to substantial negative bias in the recent estimates; and (2) relatively large numbers of false killer whales were present in waters off the island of Hawai' $i$ in June and July 1989 because of exceptional ocean or foraging conditions that year or at that time of that year. 
With regard to the first of these, aerial surveys since 1993 focused primarily on humpback whales (Megaptera novaeangliae) have also recorded sightings of odontocete cetaceans (Mobley et al. 2000). However, in those surveys more effort was devoted to circling over odontocetes than over humpback whales, given the difficulty of identifying and counting social odontocetes. Although group size estimates (and thus the mid-1990s abundance estimate from those surveys) may be negatively biased, no false killer whales were detected in the most recent aerial surveys (2000 and 2003), despite numerous sightings of 10 other species of odontocetes in the 2003 survey (Mobley 2004). Although the mark-recapture estimate from 2000 through 2004 may be biased due to heterogeneity of capture probabilities (Baird et al. 2005), the relative species sighting rates from the 1989 survey (with false killer whales representing $17 \%$ of the groups observed) compared with the more recent boat-based surveys $(1.5 \%$ of the groups observed) suggest that the population has declined.

With regard to the possibility that ocean conditions or foraging opportunities in 1989 were such that more false killer whales were in the area than usual, information from fisheries is relevant. Catch data in the main Hawaiian Islands troll fishery, available since 1987 , indicate that three of the prey species of false killer whales in Hawai' $i$, mahimahi, yellowfin tuna, and ono or wahoo (Acantbocybium solandri), had lower catches per unit effort in 1989 than the 20-yr average (Anonymous 2006). These data are taken over the entire year and throughout the main Hawaiian Islands, but they suggest that foraging opportunities were likely not substantially greater in 1989 than in other years and in fact were more likely poorer.

It is also possible, though unlikely, that the animals seen in the 1989 survey were misidentified and were in fact melon-headed whales (Peponocephala electra), which are difficult to distinguish from false killer whales and are seen in the same area in large groups. However, as noted earlier, both observers were experienced in identifying and counting cetaceans from the air; Leatherwood, in par- ticular, had extensive experience in aerial surveys for tropical odontocetes and was well known for his efforts specifically to define field characters for identifying the difficult "blackfish" group (false killer whales, melonheaded whales, pygmy killer whales [Feresa attenuata], and pilot whales [Globicephala spp.]). As noted by Leatherwood et al. (1982:123): "From the air false killer whales appear long, slim, and, in most cases, uniformly black. Juveniles are slightly lighter gray, and adults sometimes appear slightly lighter gray from the dorsal fin forward, accentuated in bright sunlight. The dorsal fin is near midbody, but the flippers appear to be unusually far forward on the body. Traveling false killer whales displace little white water when surfacing, unlike killer or pilot whales." It is relevant to note that all three of those other difficult-to-identify blackfish species were observed during the 1989 survey, including a sighting of a group of more than 400 melon-headed whales on 23 June just $4.5 \mathrm{hr}$ after a sighting of 460 false killer whales (well documented with photographs). On the same day, both pilot whales (two groups of more than 20 individuals) and pygmy killer whales (one group of about 15) were seen as well. Unfortunately, the photographs and videotapes from the survey, which would be conclusive and eliminate this element of uncertainty, have been lost since Leatherwood's death in 1997.

Taken together, all available lines of evidence seem to support the hypothesis that the island-associated population of false killer whales around the main Hawaiian Islands has declined substantially since the late 1980s. Reasons for such a decline remain uncertain but may include incidental mortality in fisheries (both inshore and offshore) and foragebase reductions that may or may not be related to fishery effects.

\section{ACKNOWLEDGMENTS}

We thank Joe Mobley for providing unpublished aerial survey data from recent years for comparative purposes, and Paul Dalzell, Kim Holland, and John Sibert for providing references. Two anonymous reviewers pro- 
vided insightful comments that helped us improve the manuscript.

\section{Literature Cited}

Anonymous. 2006. Pelagic fisheries of the western Pacific Region. 2006 Annual report. Western Pacific Regional Fishery Management Council, Honolulu, Hawai'i. Available from: www.wpcouncil.org/ pelagic.htm.

Baird, R. W., and A. M. Gorgone. 2005. False killer whale dorsal fin disfigurements as a possible indicator of long-line fishery interactions in Hawaiian waters. Pac. Sci. 59:593-601.

Baird, R. W., A. M. Gorgone, D. J. McSweeney, D. L. Webster, D. R. Salden, M. H. Deakos, A. D. Ligon, G. S. Schorr, J. Barlow, and S. D. Mahaffy. 2008. False killer whales (Pseudorca crassidens) around the main Hawaiian Islands: Long-term site fidelity, inter-island movements, and association patterns. Mar. Mamm. Sci. 24:591612.

Baird, R. W., A. M. Gorgone, D. L. Webster, D. J. McSweeney, J. W. Durban, A. D. Ligon, D. R. Salden, and M. H. Deakos. 2005. False killer whales around the main Hawaiian islands: An assessment of inter-island movements and population size using individual photo-identification. Report prepared under Order No. JJ133F04SE0120 from the Pacific Islands Fisheries Science Center, National Marine Fisheries Service. Available from: www .cascadiaresearch.org/robin/hawaii.htm.

Baird, R. W., K. M. Langelier, and P. J. Stacey. 1989. First records of false killer whales, Pseudorca crassidens, in Canada. Can. Field-Nat. 103:368-371.

Carretta, J. V., K. A. Forney, M. M. Muto, J. Barlow, J. Baker, B. Hanson, and M. S. Lowry. 2007. U.S. Pacific marine mammal stock assessments: 2006. NOAA Tech. Mem. NMFS-SWFSC-398.

Chivers, S. J., R. W. Baird, D. J. McSweeney, D. L. Webster, N. M. Hedrick, and J. C. Salinas. 2007. Genetic variation and evidence for population structure in eastern
North Pacific false killer whales (Pseudorca crassidens). Can. J. Zool. 85:783-794.

Forney, K. A., and D. Kobayashi. 2007. Updated estimates of mortality and injury of cetaceans in the Hawaii-based longline fishery, 1994-2005. NOAA Tech. Mem. NMFS-SWFSC-412.

Leatherwood, S., R. R. Reeves, W. F. Perrin, and W. E. Evans. 1982. Whales, dolphins, and porpoises of the eastern North Pacific and adjacent arctic waters: A guide to their identification. NOAA Tech. Rep. NMFS Circ. 444.

Maldini, D., L. Mazzuca, and S. Atkinson. 2005. Odontocete stranding patterns in the main Hawaiian Islands (1937-2002): How do they compare with live animal surveys? Pac. Sci. 59:55-67.

Mobley, J. R. 2004. Results of marine mammal surveys on U.S. Navy underwater ranges in Hawaii and Bahamas. Final report submitted to Office of Naval Research, Marine Mammal Program. Award no. N000140210841. Available from: http://socrates.uhwo.hawaii.edu/SocialSci/ jmobley/ONRfinal.pdf.

Mobley, J. R., S. S. Spitz, K. A. Forney, R. A. Grotefendt, and P. H. Forestell. 2000. Distribution and abundance of odontocete species in Hawaiian waters: Preliminary results of 1993-98 aerial surveys. U.S. Natl. Mar. Fish. Serv. Southwest Fisheries Science Center Admin. Rep. LJ-00-14C.

Nitta, E. T., and J. R. Henderson. 1993. A review of interactions between Hawaii's fisheries and protected species. Mar. Fish. Rev. 55 (1): 83-92.

Pooley, S. G. 1993. Hawaii's marine fisheries: Some history, long-term trends, and recent developments-fisheries of Hawaii and U.S.-associated Pacific Islands. Mar. Fish. Rev. 55 (1): 7-19.

Rhodes, K. L., D. T. Kornfeind, and M. J. Donohue. 2007. Boat-based fishery and marine mammal interactions in Hawaii's nearshore waters. Report to the Pacific Islands Regional Office, National Marine Fisheries Service, Honolulu, Hawai'i. Available from Pacific Islands Regional 
Office, 1601 Kapi'olani Boulevard, Suite 1110, Honolulu, Hawai'i 96814.

Ross, G. J. B. 1984. The smaller cetaceans of the south east coast of southern Africa. Ann. Cape Prov. Mus. Nat. Hist. 15:173410.

Shallenberger, E. W. 1981. The status of Hawaiian cetaceans. Marine Mammal Commission, Washington, D.C. Report No. MMC-77/23. Available from: National
Technical Information Service, Springfield, Virginia. PB82-109398.

Sibert, J., J. Hampton, P. Kleiber, and M. Maunder. 2006. Biomass, size, and trophic status of top predators in the Pacific Ocean. Science (Washington, D.C.) 314: 1773-1776.

Stacey, P. J., S. Leatherwood, and R. W. Baird. 1994. Pseudorca crassidens. Mamm. Species 456. 
